eventually required surgery, however, referral to an orthopaedic surgeon of all babies with unilateral loss of hip abduction in flexion is essential.

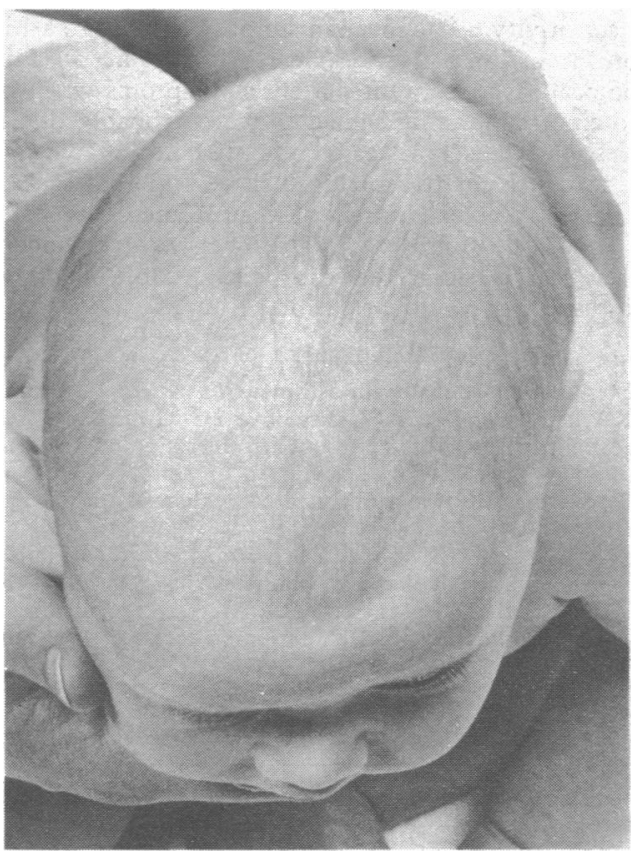

Appearances of plagiocephaly.

We thank the photographic department at Queen Mary's Hospital for Children for the illustration and Miss $S$ Wadd and Mrs R Lenham for secretarial help.

1 Dunn PM. Congenital postural deformities. Br Med Bull 1976;32:71-6.

(Accepted 9 September 1983)

Queen Mary's Hospital for Children, Carshalton, Surrey, and South

West Thames Regional Orthopaedic Training Scheme

CHRISTOPHER GOOD, FRCs, senior orthopaedic registrar

GEOFFREY WALKER, FRCS, consultant orthopaedic surgeon

Correspondence to: Mr Christopher Good, Senior Orthopaedic Registrar, St George's Hospital, London SW17.

\section{Reversible cholestatic jaundice and hyperamylasaemia associated with captopril treatment}

Captopril is a useful drug in the management of intractable heart failure and hypertension unresponsive to conventional treatment. Its adverse effects include agranulocytosis in $0.3 \%$, proteinuria in $1.2 \%$, and pruritus or dermatitis in $7 \%$ of patients. ${ }^{1}$ Although mild increases in liver enzyme activities have been noted in a few patients, ${ }^{2}$ hepatitis is not a recognised complication of treatment with captopril and has been reported in only one patient. ${ }^{3}$

\section{Case report}

A 74 year old woman was admitted to hospital on 12 December 1982 for severe left and right sided heart failure. She had a five year history of ischaemic heart disease, including two episodes of myocardial infarction, and a pacemaker had been implanted for complete atrioventricular block. Her response to treatment, including high doses of frusemide, aminophylline, spironolactone, digoxin, and isosorbide, was not satisfactory. On 2 January 1983 captopril $25 \mathrm{mg}$ by mouth thrice daily was started and was increased subsequently to $50 \mathrm{mg}$ thrice daily, resulting in the disappearance of peripheral oedema and weight loss of $11 \mathrm{~kg}$ within three weeks.
On 28 January she was readmitted because of repeated episodes of absence manifesting as unresponsiveness to external stimuli without loss of consciousness and lasting for several minutes. On admission she was aler without dyspnoea or other signs of heart failure. The pulse was regular and blood pressure was $110 / 70 \mathrm{~mm} \mathrm{Hg}$. A neurological examination and electroencephalogram were normal. Urine analysis and a complete blood count yielded normal results. Her blood urea nitrogen concentration was $19 \mathrm{mmol} / \mathrm{l}$ $(53 \mathrm{mg} / 100 \mathrm{ml})$ compared with $15 \mathrm{mmol} / \mathrm{l}(42 \mathrm{mg} / 100 \mathrm{ml})$ four weeks earlier. Serum aspartate transaminase activity was 208 IU/l (normal 10$45 \mathrm{IU} / \mathrm{l})$ compared with $26 \mathrm{IU} / 1$ on her previous admission; alkaline phosphatase activity was $350 \mathrm{IU} / 1$ (normal 30-95 IU/1) compared with $135 \mathrm{IU} / 1$; and total serum bilirubin concentration was $46 \mu \mathrm{mol} / 1(2.5 \mathrm{mg} / 100 \mathrm{ml})$. Erythrocyte sedimentation rate increased from 29 to $83 \mathrm{~mm}$ in the first hour.

During the following days her jaundice increased and generalised itching developed. There was no nausea, vomiting, or abdominal pain. The live and spleen were not enlarged. Total bilirubin concentration increased to a maximum of $123 \mu \mathrm{mol} / 1(7 \cdot 2 \mathrm{mg} / 100 \mathrm{ml}$ ) (direct $99 \mu \mathrm{mol} / 1(5 \cdot 8 \mathrm{mg} / 100 \mathrm{ml})$ ) and alkaline phosphatase activity to $1260 \mathrm{IU} / \mathrm{l}$ without a concomitant increase in serum aspartate transaminase or serum alanine transaminase activity. Serum amylase activity was $2000 \mathrm{IU} / \mathrm{ml}$ (normal 70-300) and urine amylase activity $30000 \mathrm{IU} / \mathrm{ml}$ (normal 170-2000). She remained afebrile, and al blood cultures were negative. A technetium scan showed a normal liver and spleen.

After exclusion of extrahepatic biliary obstruction the possibility of drug induced cholestatic jaundice was considered, particularly because a few days earlier, when captopril had inadvertently been stopped for 24 hours, serum amylase activities had dropped from 2000 to $800 \mathrm{IU}$, increasing to 1790 and subsequently to 2400 IU with the resumption of captopril treatment. Treatment with captopril was stopped; the jaundice resolved within one week, and alkaline phosphatase and amylase activities returned to normal within two weeks. No other drugs had been added before the developmen of jaundice or withdrawn before its resolution. Throughout the ensuing three months she continued to enjoy good health and required only minimal diuretic treatment. At no time did she complain of abdominal pain or show any other signs of acute pancreatitis.

\section{Comment}

We did not carry out rechallenge followed by a diagnostic liver biopsy in view of our patient's age and her rapid improvement after treatment with captopril was stopped. The course of events was, however, suggestive of a causal relation between captopril and hepatitis. Extrahepatic obstruction was excluded, and the absence of fever or nausea, the negative serological findings, and the predominant cholestatic pattern of liver function tests were more in keeping with drug induced than viral hepatitis. Finally, the transient improvement in serum amylase activity after captopril was inadvertently stopped temporarily and the sustained improvement after it was finally stopped strongly support our contention that captopril was responsible for the observed abnormalities.

The importance of the raised serum and urinary amylase activities in our patient is not certain, particularly in view of the lack of any clinical manifestations and the normal endoscopic retrograde cholangiopancreatogram. Although painless pancreatitis cannot be ruled out, it seems unlikely in the circumstances.

Drugs that produce rashes often cause hepatic damage with both cholestatic and hepatocellular elements. ${ }^{4}$ Thus captopril might be associated with both of these complications. Our report thus emphasises the need for increased attention to hepatic function in patients receiving treatment with captopril.

${ }^{1}$ Vidt DG, Bravo EL, Fouad FM. Drug therapy: captopril. $N$ Engl $\mathcal{H} \mathrm{Med}$ $1982 ; 306: 214-8$.

2 Elmenhary MM, Shaker A, Ramadan M, Hamza S, Tardos SS. Control of essential hypertension by captopril, an angiotensin converting enzyme inhibitor. Br $\mathcal{F}$ Clin Pharmacol 1981;11:469-75.

${ }^{3}$ Vandenburg M, Parfrey P, Wright P, Lazda E. Hepatitis associated with captopril treatment. Br $\mathcal{F}$ Clin Pharmacol 1982;11:105-6.

4 Davis M, Williams R. Hepatic disorders. In: David DM, ed. Textbook of adverse drug reactions. Oxford: Oxford University Press, 1977: 146-72.

(Accepted 9 September 1983)

Department of Medicine, Shaare Zedek Medical Centre, Jerusalem, Israel

ARI ZIMRAN, MD, resident in medicine

ABRAHAM S ABRAHAM, MD, FRCP, associate professor CHAIM HERSHKO, MD, professor of medicine

Correspondence to: Dr Chaim Hershko. 